\title{
PENERAPAN METODE K-NEAREST NIGBOAR UNTUK MENENTUKAN KUALITAS BUAH SAWIT LAYAK DITERIMA DI PT. CIPTA CHEMICAL MEDAN OIL
}

\author{
Hery, Yonata Laia, Carvirindo Fenaldi, Devi Susanti Dao, Willy Wijaya \\ Program Studi Sistem Informasi, Universistas Prima Indonesia Medan \\ JI. Sekip Jl. Sikambing No.simpang, Sei Putih Tim. I, Kec. Medan Petisah, Kota Medan, \\ Sumatera Utara 20111
}

\begin{abstract}
Abstrak
Penelitian ini membahas tentang Data Mining Untuk mentukan bagus Buah Sawit yang bagus untuk di olah Pada PT. Cipta Chemical Medan Oil Menggunakan Metode (K-NN) K-Nearest Neighbor, dimana jumlah produksi kelapa sawit tidak menentu setiap bulannya. Penelitian ini bertujuan untuk menggunakan metode $(\mathrm{K}-\mathrm{NN})$ K-Nearest Neighbor dalam pemilihan buah yang yang baik. Objek penelitian ini adalah jumlah produksi kelapa sawit sedangkan data yang digunakan merupakan data historis dari jumlah produksi tanaman kelapa sawit tahun 20172019. Dengan menggunakan metode (K - NN) K-Nearest Neighbor, Output dari Rapidminer didapatkan hasil yang baik dan berhasil melakukan penentuan buah yang layak produksi.
\end{abstract}

.Kata kunci : Kelapa Sawit, K-Nearst Neighbor, Rapidminer

\begin{abstract}
This study discusses data mining to determine good palm fruit which is good for processing at PT. Cipta Chemical Medan Oil Using the K-Nearest Neighbor (K-NN) Method, where the amount of oil palm production is uncertain every month. This study aims to use the K-Nearest Neighbor (K - NN) method in selecting a good fruit. The object of this research is the amount of oil palm production, while the data used is historical data from the amount of oil palm production in 2017-2019. By using the K-Nearest Neighbor (K - NN) method, the output from Rapidminer obtained good results and succeeded in determining fruit that was suitable for production.
\end{abstract}

Keywords : Palm Oil, K-Nearst Neighbor, Rapidminer

\section{PENDAHULUAN}

Seiring dengan perkembangannya yang pesat, Teknologi Informasi ( $\mathrm{TI}$ ) telah diaplikasikan dalam banyak kehidupan manusia. Salah satu perkembangan dari dunia TI adalah sistem pakar. Sistem pakar merupakan sistem yang berusaha mengadopsi pengetahuan pakar ke komputer, agar komputer dapat melakukan diagnosa terhadap penyakit seperti yang biasa dilakukan oleh para ahli. Sistem pakar yang baik dirancang agar dapat meniru kerja dari para ahli. Dengan adanya sistem pakar, orang awam dapat melakukan pemilihan atau diagnosa terhadap beberapa alternatif yang sebenarnya hanya dapat diselesaikan dengan bantuan para ahli. Bagi para ahli, sistem pakar juga akan membantu aktivitasnya sebagai asisten yang sangat berpengalaman, konsisten dan murah pada PT.CIPTA CHEMICAL MEDAN OIL

Metode yang digunakan dalam penelitian ini adalah metode k-Nearest Neighbor (K-NN). Metode K-NN adalah sebuah metode untuk melakukan klasifikasi terhadap objek berdasarkan data pembelajaran yang jaraknya paling dekat dengan objek tersebut. Data pembelajaran diproyeksikan ke ruang berdimensi banyak, dimana masing-masing dimensi merepresentasikan fitur dari data. Ruang ini dibagi menjadi bagian-bagian berdasarkan klasifikasi data 
pembelajaran. Sebuah titik pada ruang ini ditandai kelas $c$ jika kelas $c$ merupakan klasifikasi yang paling banyak ditemui pada $\mathrm{k}$ buah tetangga terdekat titk tersebut. Dekat atau jauhnya tetangga biasanya dihitung berdasarkan jarak Euclidean.

Berdasarkan uraian yang disebutkan di atas, maka akan dibangun sebuah aplikasi sistem pendukung keputusan dalam penentuan kualitas buah sawit layak diterima "penerapan metode k-nearest nigboar untuk menentukan kualitas buah sawit layak diterima di pt. cipta chemical medan oil".

\section{KAJIAN PUSTAKA}

\subsection{Sistem Pakar}

Sistem pakar merupakan cabang dari Artifical Intelligence (AI) yang cukup tua karena sistem ini mulai dikembangkan pada pertengahan 1960. Sistem pakar yang muncul pertama kali adalah General-pupose problem solver (GPS) yang dikembangkan oleh Newel dan Simon. Sampai saat ini sudah banyak sistem pakar yang dibuat, seperti MYCIN untuk diagnosis penyakit, DENDRAL untuk mengidentifikasi struktur molekul campuran yang tak dikenal, XCON dan XSEL untuk membantu konfigurasi sistem komputer besar, SOPHIE untuk analisis sirkuit elektronik, Prospector digunakan di bidang geologi untuk membantu mencari dan menemukan deposit, FOLIO digunakan untuk membantu memberikan keputusan bagi seorang manager dalam stok dan investasi, DELTA dipakai untuk pemeliharaan lokomotif listrik diesel, dan sebagainya (Sutojo dkk, 2013:159-160).

Sistem pakar adalah aplikasi berbasis komputer yang digunakan untuk menyelesaikan masalah sebagaimana yang dipikirkan oleh pakar. Pakar yang dimaksud di sini adalah orang yang mempunyai keahlian khusus yang dapat menyelesaikan masalah yang tidak dapat diselesaikan oleh orang awam. Sebagai contoh, dokter adalah seorang pakar yang mampu mendiagnosis penyakit yang diderita oleh pasien serta dapat memberikan pemeriksaan terhadap penyakit tersebut (Kusrini, 2013:3).

Sistem pakar adalah sistem komputer yang ditujukan untuk meniru semua aspek (emulates) kemampuan pengambilan keputusan (decision making) seorang pakar. Sistem pakar memanfaatkan secara maksimal pengetahuan khusus layaknya seorang pakar untuk memecahkan masalah (Rosnelly, 2013:2). Pengetahuan yang dimuat ke dalam sistem pakar dapat berasal dari seorang pakar atau pengetahuan yang berasal dari buku, jurnal, majalah dan dokumentasi yang dipublikasikan lainnya, serta orang yang memiliki pengetahuan meskipun bukan ahli. Istilah sistem pakar sering disinonimkan dengan sistem pakar berbasis pengetahuan (knowledge based expert system) (Rosnelly, 2013:3).

Sistem pakar adalah aplikasi komputer yang ditujukan untuk membantu pengambilan keputusan atau pemecahan persoalan dalam bidang yang spesifik. Sistem bekerja dengan menggunakan pengetahuan dan metode analisis yang telah didefinisikan oleh pakar yang sesuai dengan bidang keahliannya (Hayadi, 2016:1).

Secara umum, sistem pakar (expert system) adalah sistem yang berusaha mengadopsi pengetahuan manusia ke komputer, agar komputer dapat menyelesaikan masalah seperti yang biasa dilakukan oleh para ahli. Dengan sistem pakar ini, orang awam pun dapat menyelesaikan masalah yang cukup rumit yang sebenarnya hanya dapat diselesaikan dengan bantuan para ahli. Bagi para ahli, sistem pakar ini juga akan membantu aktivitasnya sebagai asisten yang sangat berpengalaman (Silmi, dkk, 2013:32)..

\section{METODOLOGI PENELITIAN}

\subsection{Data Dari Penelitian}

Proses analisa mencakup analisa kriteria dan analisa proses pemilihan buah kelapa sawit yang layak diterima dalam PT. Cipta Chemical Medan Oil dengan menggunakan metode k-Nearest Neighbor (K-NN), serta pemodelan sistem.

\subsubsection{Analisa Kriteria}


Adapun kriteria yang digunakan dalam proses pemilihan buah kelapa sawit adalah sebagai berikut:

1. Anggaran, yaitu anggaran yang dimiliki oleh perusahaan untuk membeli buah sawit dari supplier. Kriteria yang digunakan dapat dilihat pada tabel 3.1.

\section{Tabel 3.1. Kriteria Anggaran}

\begin{tabular}{lll}
\hline Dari & Sampai & Nilai \\
1.550 & 1.600 & 1 \\
1.601 & 1.650 & 2 \\
1.651 & 1.700 & 3 \\
1.701 & 1.750 & 4 \\
1.751 & 1.800 & 5 \\
1.801 & 1.850 & 6 \\
1.851 & 1.900 & 7 \\
1.901 & 1.950 & 8 \\
\hline
\end{tabular}

2. Jenis buah, yaitu jenis buah kepala sawit yang diinginkan. Kriteria yang digunakan dapat dilihat pada tabel 3.2.

Tabel 3.2. Kriteria Jenis

\begin{tabular}{ll}
\hline Jenis & Nilai \\
Dura & 1 \\
Pisifera & 5 \\
Tenera & 10 \\
\hline
\end{tabular}

3. Tingkat Rademen, yaitu tingkat rademen minyak sesuai dengan buah kelapa sawit yang dipilih. Kriteria yang digunakan dapat dilihat pada tabel 3.3.

Tabel 3.3. Kriteria Tingkat Rademen Minyak

\begin{tabular}{ll}
\hline $\begin{array}{l}\text { Tingkat } \\
\text { Minyak }\end{array}$ & Rademen \\
& Nilai \\
$11 \%-14 \%$ & 1 \\
$14 \%-18 \%$ & 2 \\
$18 \%-23 \%$ & 3 \\
$23 \%-26 \%$ & 4 \\
\hline
\end{tabular}

4. Umur pokok, yaitu umur pokok yang dipilih. Kriteria yang digunakan dapat dilihat pada tabel 3.4.

Tabel 3.4. Kriteria Umur Pokok

\begin{tabular}{ll}
\hline Umur Pokok & Nilai \\
15 bln -2 thn & 1 \\
2 thn -3 thn & 2 \\
3 thn -5 thn & 3 \\
5 thn -10 thn & 4 \\
10 thn $>$ & 5 \\
\hline
\end{tabular}




\subsubsection{Analisa Proses Pemilihan K-NN}

Sebagai contoh, data training yang digunakan sebagai perhitungan jarak dalam metode K-NN seperti terlihat pada tabel 3.5 .

Tabel 3.5. Data Training

\begin{tabular}{|c|c|c|c|c|c|}
\hline $\begin{array}{l}\text { Nomor } \\
\text { Data }\end{array}$ & $\begin{array}{l}\text { Nama } \\
\text { Supplier }\end{array}$ & Anggaran & Jenis & $\begin{array}{l}\text { Rademen } \\
\text { Minyak }\end{array}$ & Umur Pokok \\
\hline 00001 & Jampi & 1.555 & Dura & $11 \%-14 \%$ & 3 thn -5 thn \\
\hline 00002 & Hendrik & 1.875 & Tenera & $23 \%-26 \%$ & 10 thn $>$ \\
\hline 00003 & Rini & 1.820 & Tenera & $18 \%-23 \%$ & 3 thn -5 thn \\
\hline 00004 & Meroke & 1.580 & Dura & $11 \%-14 \%$ & 3 thn -5 thn \\
\hline 00005 & Suaranta & 1.795 & Pisifera & $14 \%-18 \%$ & 2 thn -3 thn \\
\hline 00006 & Yusdi & 1.585 & Dura & $11 \%-14 \%$ & 3 thn -5 thn \\
\hline 00007 & Zawe & 1.895 & Tenera & $23 \%-26 \%$ & 10 thn $>$ \\
\hline 00008 & $\begin{array}{l}\text { PT. Bandar } \\
\text { Meriah }\end{array}$ & 1.885 & Tenera & $23 \%-26 \%$ & 5 thn -10 thn \\
\hline 00009 & $\begin{array}{l}\text { Zahrul } \\
\text { Fuadi }\end{array}$ & 1.755 & Pisifera & $14 \%-18 \%$ & 2 thn -3 thn \\
\hline 00010 & Boang & 1.735 & Pisifera & $14 \%-18 \%$ & 2 thn -3 thn \\
\hline
\end{tabular}

\subsubsection{Pemodelan Sistem}

Use case adalah salah satu diagram Unified Modeling Language (UML) yang dapat digunakan untuk menganalisis dan memodelkan sistem. Gambar 3.1 menunjukkan interaksi antara pengguna dan sistem di dalam diagram use case. 


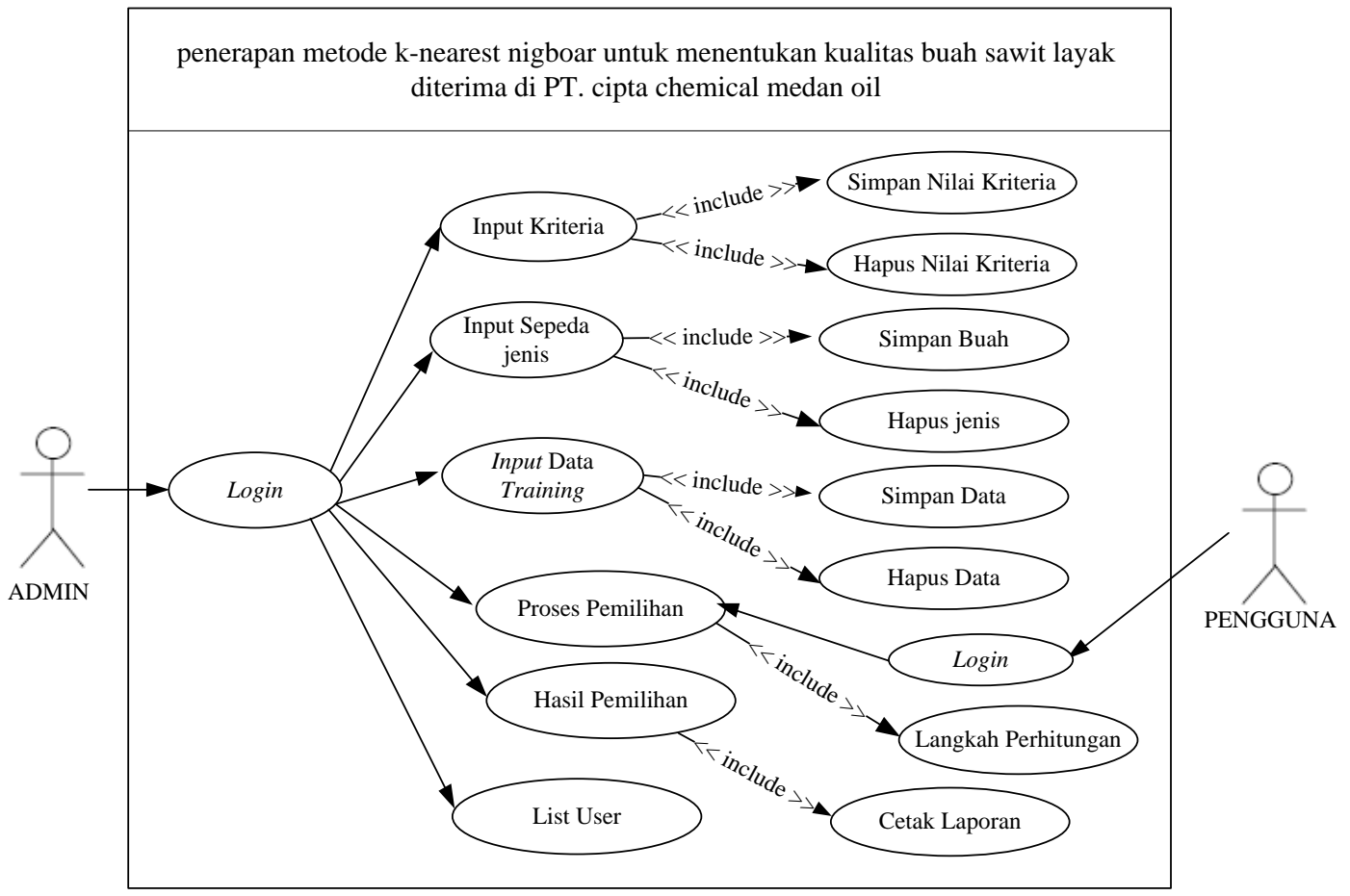

Gambar 1. Diagram Use Case dari Aplikasi

Dalam notasi Use Case, hubungan "include" antar use case, berarti use case X menggunakan use case $\mathrm{Y}$ sepenuhnya. Proses yang terjadi di dalam aplikasi juga dapat digambarkan dengan activity diagram seperti terlihat pada gambar 2 berikut.

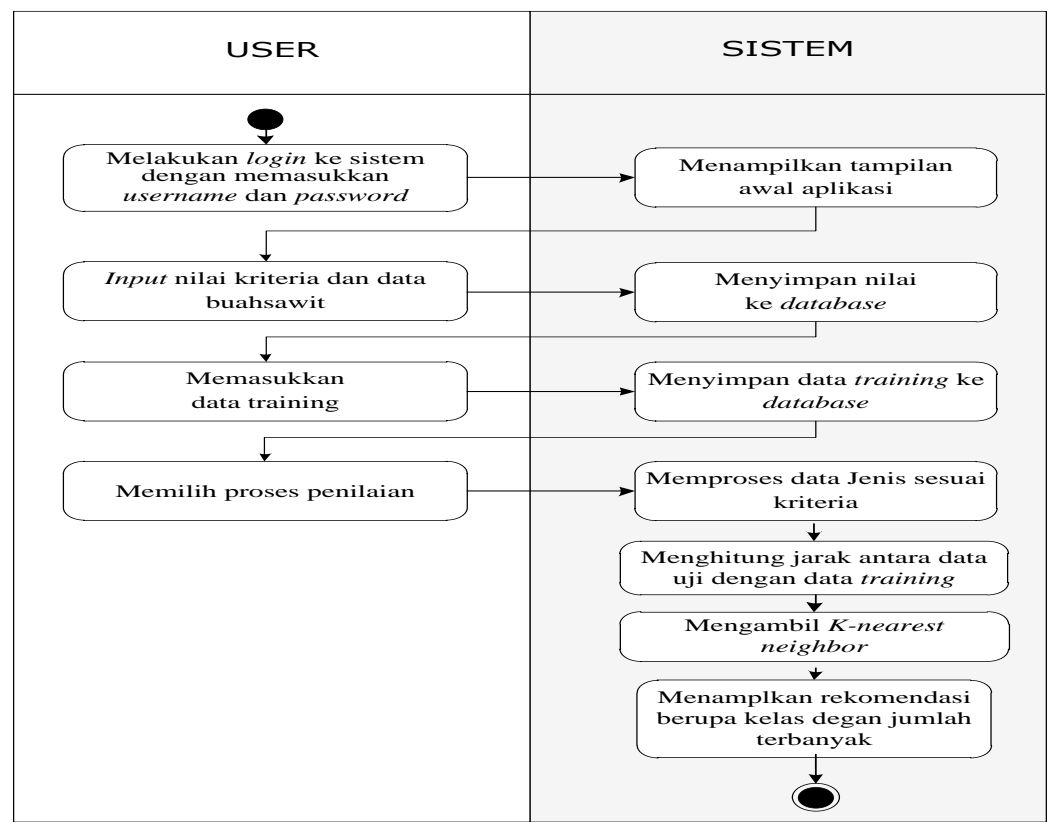

Gambar 2. Activity Diagram dari Sistem

\section{REFERENSI}

[1] Adi, N. 2010. Rekayasa Perangkat Lunak Berorientasi Objek dengan Metode USDP. 
Yogyakarta: Andi. Abdo, E. 2013. Modern Motorcycle Technology. Cengage Learning.

[2] Anshori, L. 2017. Implementasi Metode K-Nearest Neighbor untuk Rekomendasi Keminatan Studi. Jakarta: Universitas Brawijaya. (jurnal).

[3] Dharwiyanti dan Wahono. 2013. Pengantar Unified Modeling Language (UML). Kuliah IImuKomputer.com. Febiantoro. 2014. Daftar Simbol Diagram UML. Bandung: Universitas Widyatama.

[4] Hadi, F. 2015. Implementasi Sistem Pakar Berbasis Aturan untuk Diagnosa Produktivitas Ternak Ayam Ras Dengan Menggunakan Metode Forward Chaining. Padang: Universitas Putra Indonesia.

[5] Hayadi. B.H. 2016. Sistem Pakar. Yogyakarta: Deepublish. Kawasan, M. 2013. Penciptaan Sepeda Motor dari Sepeda hingga Mesin Empat Tak. Edisi Media November 2013.

[6] Kusrini. 2008. Sistem Pakar. Yogyakarta: Andi. Kusrini dan Luthfi, E.T. 2009. Algoritma Data Mining. Yogyakarta: Andi.

[7] Mustakim dan Giantika. 2016. Algoritma K-Nearest Neighbor Classification Sebagai Sistem Prediksi Predikat Prestasi Mahasiswa. Riau: UIN Suska.

[8] Prasetyo, E. 2012. Data Mining - Konsep dan Aplikasi Menggunakan MATLAB. Yogyakarta: Andi Offset. Rosnelly, R. 2012. Konsep dan Teori Sistem Pakar. Yogyakarta: Andi.

[9] Silmi, M. dkk. 2013. Sistem Pakar Berbasis Web dan Mobile Web untuk Mendiagnosis Penyakit Darah pada Manusia dengan Menggunakan Metode Inferensi Forward Chaining. Semarang: Universitas Diponegoro.

[10] Sukma, dkk. 2014. K-Nearest Neighbor Information Retrieval (Sistem Temu Kembali Informasi). Jakarta: Universitas Airlangga. Vittore, C. 2016. Motorcycle Dynamics. Lulu. ISBN 978-1-4303-0861-4.

[11] Wahana Komputer. 2010. Panduan Aplikatif dan Solusi (PAS) Membuat Aplikasi Client Server dengan Visual Basic 2008. Yogyakarta: Andi Offset. Wahana Komputer. 2010. SQL Server 2008 Express. Yogyakarta: Andi.

[12] Wulandari. 2017. Minat Masyarakat Jepang Terhadap Sepeda Motor Ootobai Ni Taishite No Nihonshokai No Kyoumi. Medan: USU.

[13] Sarosa. 2009. Sistem Informasi Akuntansi. Jakarta: Gransindo.

[14] Sutojo, T. dkk. 2011. Kecerdasan Buatan. Yogyakarta: Andi.

[15] Winarto, E. dan Zaki, A. 2010. Dasar-Dasar Pemograman dengan Visual Basic 2010. Jakarta: PT. Elex Media Komputindo. 